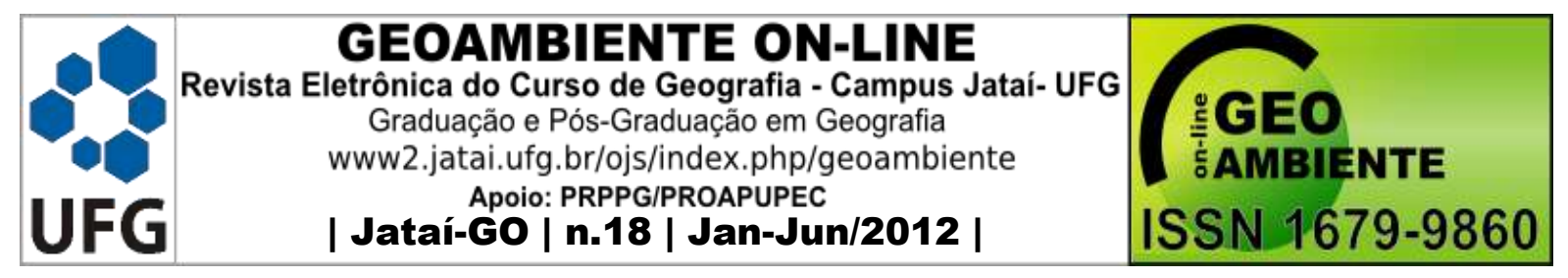

\title{
RESÍDUOS SÓLIDOS ORGÂNICOS PROVENIENTES DA EXTRAÇÃO DE OLEAGINOSAS PARA BIODIESEL E SEUS POTENCIAIS DE USO
}

\author{
Ravena de Moraes Gentili ${ }^{1}$ Juan Carlos Valdés Serra ${ }^{2}$, Renato Brito de Castro $^{2}$
}

(1 - Universidade Federal do Tocantins, Mestranda em Agroenergia UFT (ravgentil@gmail.com, 2 - Universidade Federal do Tocantins, Professor do programa de Mestrado em Agrenergia-UFT, juancs@uft.edu.br, Universidade do Estado do Pará, Engenheiro de Produção UEPA, rebricas@ hotmail.com)

\section{Resumo}

O presente artigo apresenta uma revisão sobre potencialidades da utilização de resíduos sólidos orgânicos da indústria de extração de óleo vegetais de dendê, soja, mamona e girassol; para a produção de biodiesel. O cenário atual e futuro da produção de biodiesel no Brasil indicam um crescimento significativo do setor até o ano de 2020. Com a implantação da obrigatoriedade de proporções maiores deste combustível no óleo diesel, teremos conseqüentemente, a geração de uma grande quantidade de descartes sólidos orgânicos com grande potencial e possibilidades de utilização no mercado. Esses resíduos sólidos orgânicos podem representar ganhos econômicos na região onde serão gerados. A pesquisa foi realizada através de revisão bibliográfica dos principais estudos relacionados a este tema, avaliando as culturas da soja, dendê, mamona e girassol; ressaltando seus benefícios econômicos, sociais e ambientais e considerando as potencialidades regionais do Brasil. Os resultados obtidos mostraram que a cultura que deverá ganhar um grande destaque nos próximos anos é o dendê, visto que é a oleaginosa da qual se extrai maior quantidade de óleo, e seus resíduos apresentam grandes potenciais para o mercado, trazendo não somente benefício econômico quanto ambiental, e tendo o norte e parte do nordeste Brasileiro clima e estrutura favorável ao desenvolvimento desta oleaginosa. Há necessidade de mais investimento em pesquisa sobre a utilização correta destes produtos, porém estudos realizados já mostram seu potencial para a

\footnotetext{
Artigo recebido para publicação em 24 de Novembro de 2011

Artigo aprovado para publicação em 03 de Junho de 2012
} 


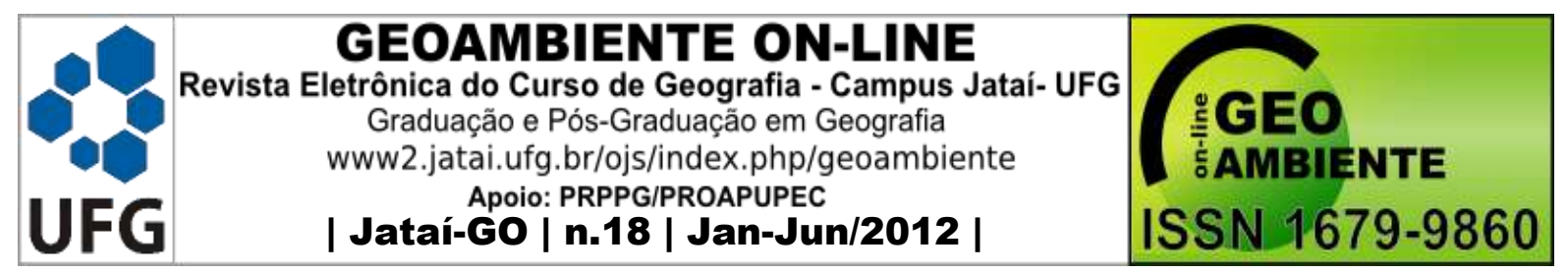

geração de renda e desenvolvimento não somente para a cadeia produtiva do biodiesel, mas para toda a região onde estão inseridos.

Palavras-chave: Biodiesel, resíduos, oleaginosas, co-produtos do biodiesel.

\title{
Abstract \\ SOLID ORGANIC WASTE FROM THE EXTRACTION OF OIL FOR BIODIESEL AND POSSIBILITIES OF USE
}

This article presents a review of the potential use of organic solid waste industry to extract vegetable oil from palm oil, soyabean, rapeseed and sunflower, for the production of biodiesel. The current scenario and future of biodiesel production in Brazil indicate a significant growth sector by the year 2020. With the implementation of the requirement of larger proportions of the fuel in the diesel, then we will have to generate a large amount of organic solids discharges with great potential and possibilities of using the market. These may represent organic solid waste in the region where economic gains will be generated. The survey was conducted through literature review of major studies related to this issue, evaluating the soybean, palm, castor and sunflower, reinforcing their economic, social, and environmental and considering the regional potential of Brazil. The results showed that the culture that is expected to gain a high profile in the coming years is the palm, since it is the crop from which to extract more oil, and their residues have great potential for the market, bringing not only economic benefit as environment, and taking the north and northeastern part of Brazil climate conducive to the development and structure of thisoilseed. There is need for more investment in research on the use of these products, but studies have already shown their potential for income generation and development not only for the biodiesel production chain, but for the whole region where they live.

Keywords: Biodiesel, waste oil, biodiesel co-products.

\section{Resumen}

\author{
RESIDUOS SÓLIDOS ORGÁNICOS DE LA EXTRACCIÓN
}

EL ACEITE DE BIODIESEL Y SU USO POTENCIAL 


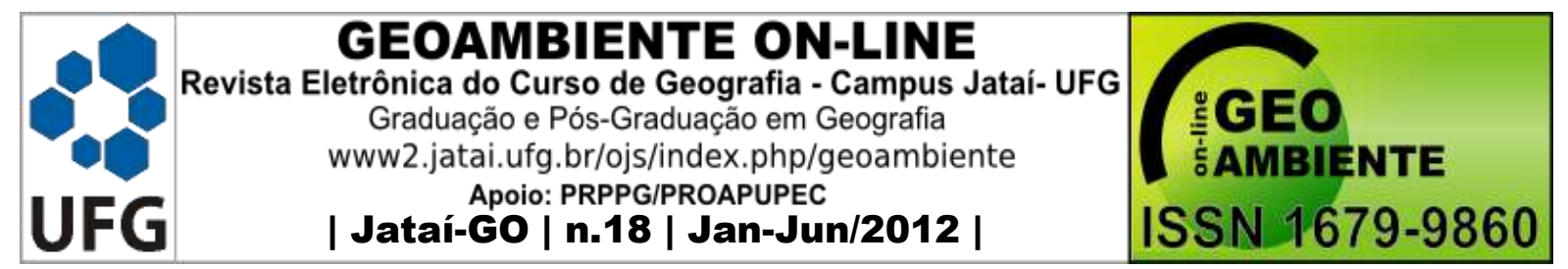

Este artículo presenta una visión general del uso potencial de la industriaorgánica de los residuos sólidos de la extracción de aceite de la planta de aceite de palma, soja, ricino y girasol, para la producción de biodiesel. El escenarioactual y futuro de la producción de biodiesel en Brasil indican un sector deimportante crecimiento para el año 2020. Con la aplicación de la exigencia demayores proporciones del combustible en el motor diesel, entonces tendrá que generar una gran cantidad de vertidos sólidos orgánicos con un gran potencial yposibilidades de utilizar el mercado. Estos residuos sólidos orgánicos pueden representar beneficios económicos en la región donde se generan. La encuesta fue realizada a través de revisión de la literatura de los estudios más importantes relacionados con este tema, la evaluación de la soja, palma, ricino y girasol, y elrefuerzo de su económica, social y ambiental teniendo en cuenta el potencialregional de Brasil. Los resultados mostraron que la cultura que se espera obtener un alto perfil enlos próximos años es la palma, ya que es el cultivo de donde extraer mayores cantidades de petróleo y sus residuos tienen un gran potencial para el mercado, con lo que no sólo beneficios económicos, como medio ambiente, y tomando la parte norte y noreste de Brasil, el clima propicio para el desarrollo y la estructura de esta oleaginosa. No hay necesidad de una mayor inversión en investigación sobre el uso correcto de estos productos, pero los estudios ya han demostrado su potencial para la generación de ingresos y el desarrollo no sólo para la cadena deproducción de biodiesel, pero para toda la región donde se insertan.

Palabras Clave: biodiesel, aceite usado, biodiesel co-productos.

\section{1 - Introdução}

O crescimento acelerado da urbanização e conseqüentemente da industrialização das sociedades modernas tem originado uma produção exponencial de resíduos sólidos, problema que necessita ser encarado como prioridade a fim de se encontrarem as melhores soluções técnicas para minimizá-lo (RUSSO, 2003).

No cenário de busca de medidas sustentáveis para controlar e/ou atenuar os efeitos indesejáveis de resíduos em geral, têm-se optado, nos últimos anos, pelo uso de produtos sustentáveis. Assim tem-se utilizado de biocombustíveis, que são "combustíveis produzidos a partir da biomassa- produtos vegetais ou compostos de origem animal" em associação com combustíveis fósseis, como forma de reduzir o problema destes últimos ao meio ambiente (PETROBRÁS, 2009). 


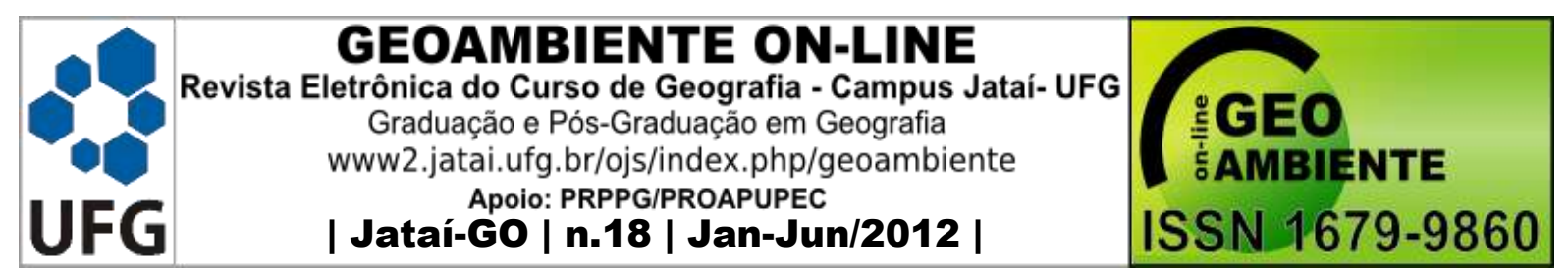

Sob o conceito de biomassa, três grandes vertentes dominam o mercado da agricultura de energia: os derivados de produtos intensivos em carboidratos ou amiláceos, como o etanol; os derivados de lipídios, como o biodiesel; e os derivados de madeira e outras formas de biomassa,como briquetes ou carvão vegetal (SCHNEIDER et al.2006).

Para a obtenção do óleo usado para a produção de biodiesel, as sementes das oleaginosas passam pelo processo de extração, pois são basicamentes constituidas por uma parte fibrosa e outra oleosa. Durante as etapas de extração, ocorre a separação do óleo e da massa restante através de uma tela filtrante (SCHNEIDER et al.2006).

A produção de biodiesel, dependendo da cultura, apresenta rendimento diferente, podendo gerar maior ou menor volume de resíduos. No caso da mamona (Ricinus communis L.) a quantidade deste resíduo é bastante significativa, incluindo o descarte da casca das bagas e a torta celulósica processada. A existência e o destino desses descartes devem ser considerados como uma etapa importante do processo da extração de óleo para o biodiesel, pois, as legislações ambientais têm sido cada vez mais rigorosa em relação às unidades de beneficiamento da matéria vegetal com relação ao destino dos resíduos destas (RANGEL et al.2004).

A produção desses resíduos representa perda de biomassa e de nutrientes, e está associado ao desperdício na utilização de insumos, e principalmente aos materiais que são gerados ao longo da cadeia agroindustrial, e, que não possuem valor econômico evidente, mas que tem sido, ultimamente, considerados na receita da indústria e por isso tem sido utilizado para se aferir receitas com o mesmo pela indústria (ONG BANCO DEALIMENTOS, 2004).

No ano de 2004 foi criado no Brasil o Programa Nacional de Produção e Uso do Biodiesel (PNPB), regulamentado em 2005, este programa, o qual tem metas de caráter social, econômico e ambiental e em 2010 já contabilizou expressivos ganhos econômicos e principalmente ambientais. Assim, em 2008, segundo dados da ANP (2009), o uso do biodiesel em 2008 permitiu uma redução na importação de diesel de petróleo de 1,1 bilhões de litros. Considerando a entrada do B5 no início de 2010, se esse percentual de mistura se mantiver até o ano de 2013, o que é pouco provável, visto que os percentuais de mistura têm se antecipado aos prazos previstos na Lei, a redução na importação de diesel será ainda mais expressiva, o que demandará a produção de bilhões de litros de biodiesel nos anos seguintes e consequentemente aumentará a produção de resíduos, o que irá exigir uma destinação adequada. 


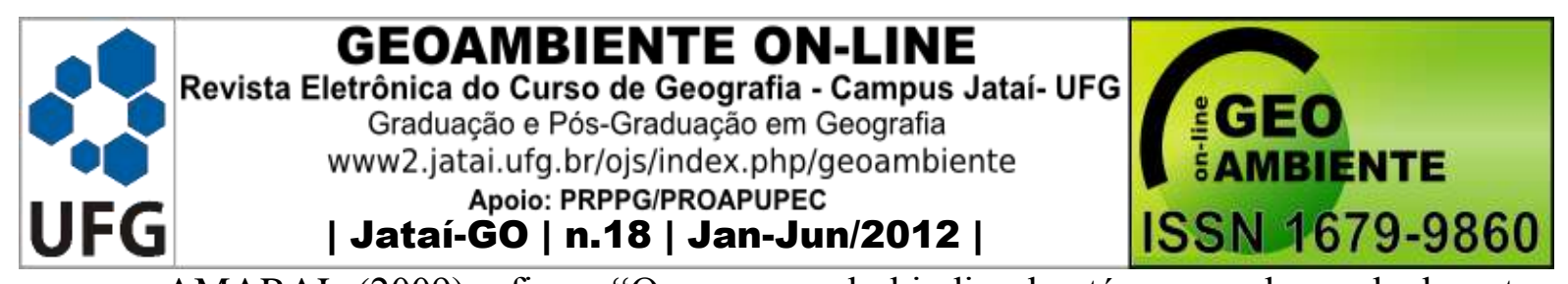

AMARAL (2009), afirma “O consumo de biodiesel está crescendo gradualmente e deverá atingir 3,1milhões de toneladas em 2020", e atrelado ao mercado de óleo está a necessidade do surgimento de indústrias que beneficiem volumes gerados de resíduos sólidos resultantes do processo de produção de óleos vegetais, e conseqüentemente forneçam novas matérias-primas aproveitando eficientemente esses descartes (SCHNEIDER et al.2006).

Segundo OLIVEIRA et al. (2005) os resíduos sólidos orgânicos são materiais de origem vegetal e animal, cujo acúmulo não é desejável no ambiente, podendo ocasionar conseqüências indesejáveis à sociedade.

Nesta perspectiva, o presente artigo pretende discutir alguns destinos e potencialidades de (re)utilizações dos resíduos provenientes das indústrias de processamento das culturas produtoras de óleo; soja, dendê, mamona e girassol, discutindo a necessidade de se agregar valor de mercado, além de sua viabilidade de uso e consequência social, econômica e ambiental.

\section{2- Metodologia}

Nesta pesquisa, será apresentada uma revisão bibliográfica dos principais estudos relacionados a este tema, onde concentro informações das várias possibilidades de utilização destes produtos sólidos resultantes das indústrias de extração de óleo, para atender a demanda de Biodiesel, ressaltando seus benefícios econômicos, sociais e ambientais e considerando as potencialidades regionais do Brasil.

A Pesquisa foi realizada utilizando parâmetros para análise comparativa de produção de resíduos como: participação de óleos vegetais na produção de biodiesel, participação nacional das culturas em questão, teor de óleo no fruto (\%), teor de resíduos no fruto (\%).

Para a melhor compreensão do potencial das culturas oleaginosas foram ilustradas em tabelas com o Ciclo da cultura, Origem do óleo e Oferta nacional extraídas de NOGUEIRA et al. (2006).

Com base nessas fundamentações, foram descritas as potencialidades de (re)utilização dos resíduos sólidos das culturas: Dendê (Elaeais guineensis Jaquim), Mamona (Ricinus communis L.), Girassol (Helianthus annuus) e Soja (Glycine max (L.) Merrill); analisando a inclusão e o uso de cada uma delas na cadeia produtiva do biodiesel.

Os dados encontrados na literatura abordam sistemas produtivos das culturas que são matérias-primas para biodiesel, processo de extração de óleo, perspectiva do biodiesel e usos 


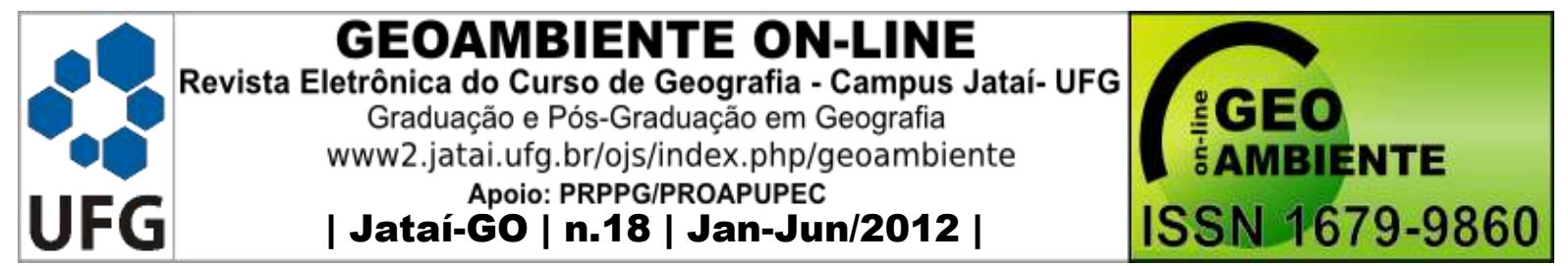

de resíduos agrícolas das culturas oleaginosas. A pesquisa foi realizada no período de setembro à outubro de 2012.

\section{3 - Resultados e discussões}

O Brasil dispõe de condições excelentes para o plantio de oleaginosas com o propósito de produzir biodiesel, são diversas as alternativas para a produção de óleos vegetais, sendo um país tropical e com dimensões continentais, tem- se o desafio do aproveitamento das potencialidades regionais no que tange a produção de óleo vegetal para bicombustível. Dentre as varias alternativas, merecem destaque a soja, cujo óleo corresponde a $90 \%$ da produção nacional de óleos vegetais, o dendê e o girassol pelo rendimento de óleo e a mamona pela resistência à seca (NOGUEIRA, 2005).

Verifica-se na tabela 1 as características das quatro culturas e seus potenciais para o uso energéticos. O dendê é a cultura da qual se extrai uma maior quantidade de óleo.

Já na tabela 2 observa-se as diferentes espécies com a porcentagem de participação no mercado nacional, ficando evidente que a soja lidera o ranking nacional.

Na tabela 3 temos uma comparação das culturas, mostrando seus respectivos teores de óleo e geração de resíduos em porcentagem, aqui verificamos que a soja é o grão que possui menor concentração de óleo e maior quantidades de resíduos.

Tabela 1- Características das oleaginosas com potencial para uso de fins energéticos

\begin{tabular}{lllcc}
\hline Espécie & $\begin{array}{l}\text { Origem } \\
\text { Do óleo }\end{array}$ & Oferta regional & $\begin{array}{l}\text { Meses de } \\
\text { Colheita / ano }\end{array}$ & $\begin{array}{l}\text { Rendimento } \\
\text { (t óleo/ha) }\end{array}$ \\
\hline Dendê/Palma & Amêndoa & Norte & 12 & $3,0-6,0$ \\
Girassol & Grão & Centro.Oeste/Sul & 3 & $0,5-1,9$ \\
Mamona & Grão & Nordeste & 3 & $0,5-0,9$ \\
Soja & Grão & Todas & 3 & $0,2-0,4$ \\
\hline
\end{tabular}

Fonte: NOGUEIRA et al. ( 2006).

Tabela 2- Importância no mercado nacional de óleos vegetais.

\begin{tabular}{lc}
\hline Espécie & $\begin{array}{c}\text { \% de } \\
\text { participação }\end{array}$ \\
\hline Soja & $89,6 \%$ \\
Dendê/Palma & $2,5 \% ;$ \\
Mamona & $1,1 \%$ \\
Girassol & $0,4 \%$ \\
\hline Fonte: Adaptada de ABIOVE (2006)
\end{tabular}




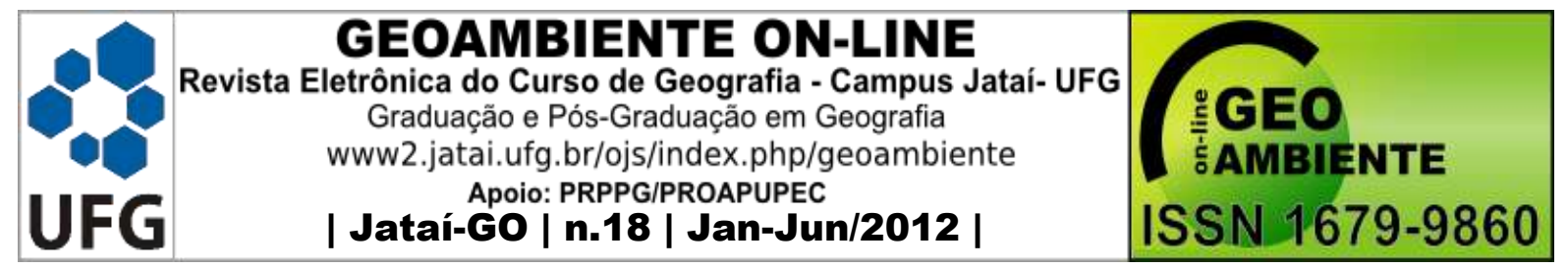

Tabela 3: Teor de óleo no fruto e quantidade de resíduos.

\begin{tabular}{|c|c|c|}
\hline Espécie & $\begin{array}{c}\text { Óleo no fruto } \\
(\%)\end{array}$ & $\begin{array}{c}\text { Resíduos por fruto } \\
(\%)\end{array}$ \\
\hline Soja & $\begin{array}{l}\text { Óleo } 18,13 \% \\
\text { (SBARDELOTTOI \& } \\
\text { GIDEON, 2008) }\end{array}$ & $\begin{array}{c}\text { Farelo 70,74\% } \\
\text { Casca 2,81\% } \\
\text { (SBARDELOTTOI \& } \\
\text { GIDEON, 2008) }\end{array}$ \\
\hline Dendê/Palma & $\begin{array}{l}20 \% \text { Óleo de palma bruto/5\% } \\
\text { Óleo de palmiste } \\
\text { (FURLAN, 2006) }\end{array}$ & $\begin{array}{c}\text { 1,5\% Torta de palmiste, } \\
3,5 \% \text { Engaços, } 22 \% \text { Fibras, } \\
12 \% \text { Cascas. } \\
\text { (FURLAN, 2006) }\end{array}$ \\
\hline Mamona & $\begin{array}{c}\text { 35\% òleo } \\
\text { (MENDES,2005) }\end{array}$ & $\begin{array}{c}\text { 30\% Casca } \\
\text { 35\% Torta } \\
(\text { MENDES,2005) }\end{array}$ \\
\hline Girassol & $\begin{array}{c}\text { 45\% de óleo } \\
\text { (CACERES,2008) }\end{array}$ & $\begin{array}{c}\text { Casca,25\% } \\
\text { Farelo30\% } \\
\text { (CACERES,2008) }\end{array}$ \\
\hline
\end{tabular}

Fonte: Adaptado de vários autores, anteriormente mencionados.

Levando em consideração a entrada do B5 (adição de 5\% de biodiesel ao diesel) no início de 2010 o país teve uma demanda de 2,2 a 2,4 bilhões de litros de biodiesel, se esse percentual se mantiver até 2013 teremos uma demanda prevista de 2,8 bilhões de litros como mostar a figura 1(GOES et al, 2009). Com a obrigatoriedade de aumento da proporção de biodiesel no diesel, aumentará a demanda de óleos vegetais, o que resultará na produção de uma grande quantidade de resíduos.

Analisando o gráfico da Figura 2 observa- se que com o aumento da produção de biodiesel em 2012 para 2,7 bilhões de litros (EPE, 2011), demandará o aumento na produção de oleaginosas, as quais se continuarem com o mesmo percentual de importância nacional de 84,52\% (ANP, 2009) na produção de óleo vegetais, produzirá em 2012 grandes quantidades 


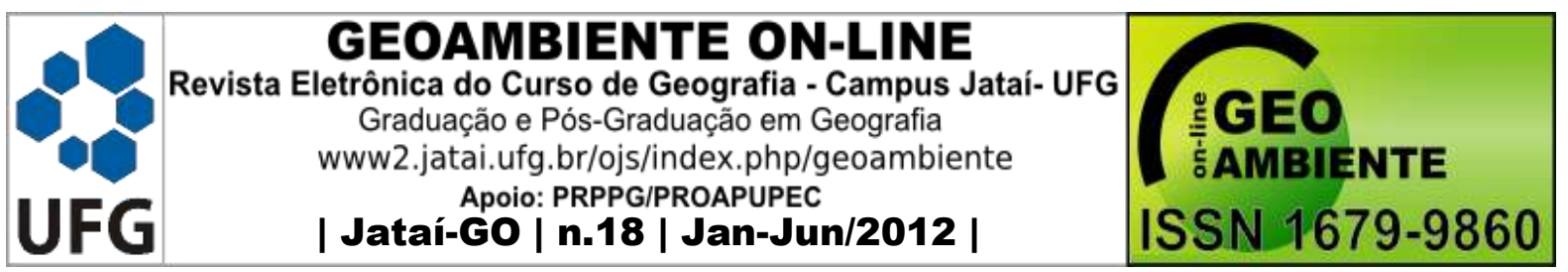

de resíduos, que no caso da soja, mostrou-se em um percentual mais elevados do que as outras culturas, tal fato se deve pela expressão de áreas cultivadas. De forma geral as culturas apresentam geração de resíduos acima da produção de óleo.

Figura 1- Estimativa da produção de Biodiesel para 2013

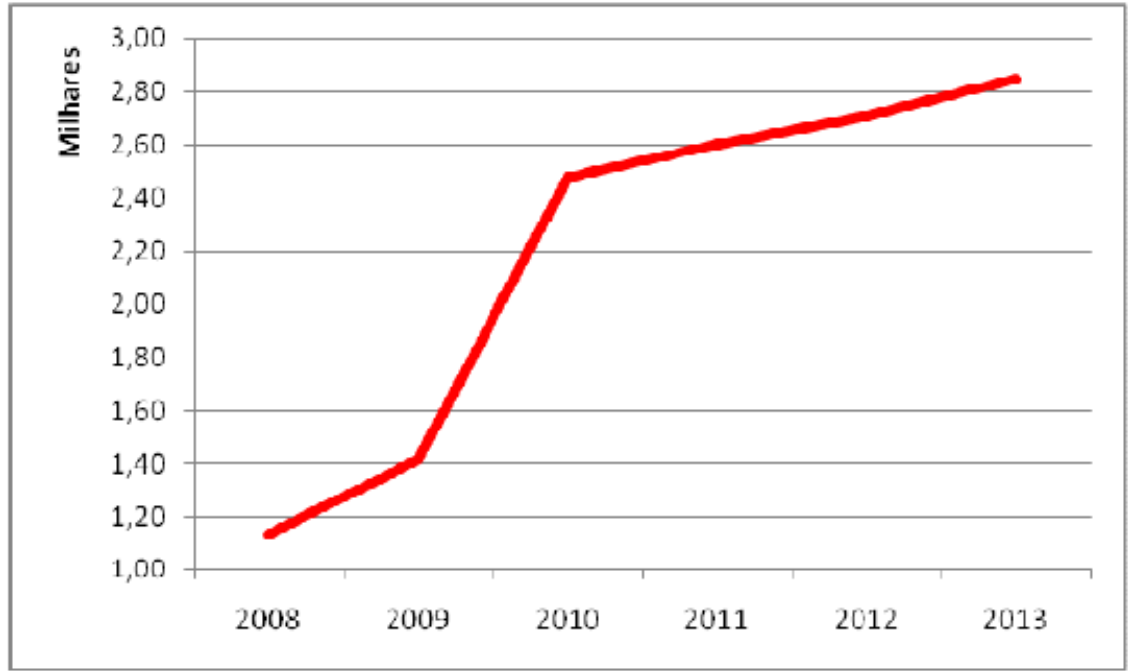

Fonte: Adaptado EPE, (2011).

Figura 2- Estimativa para a produção de biodiesel em 2011 /Participação de oleaginosas na produção de biodiesel/ Participação da cultura na produção de óleo nacional/ Geração de resíduos na cultura.

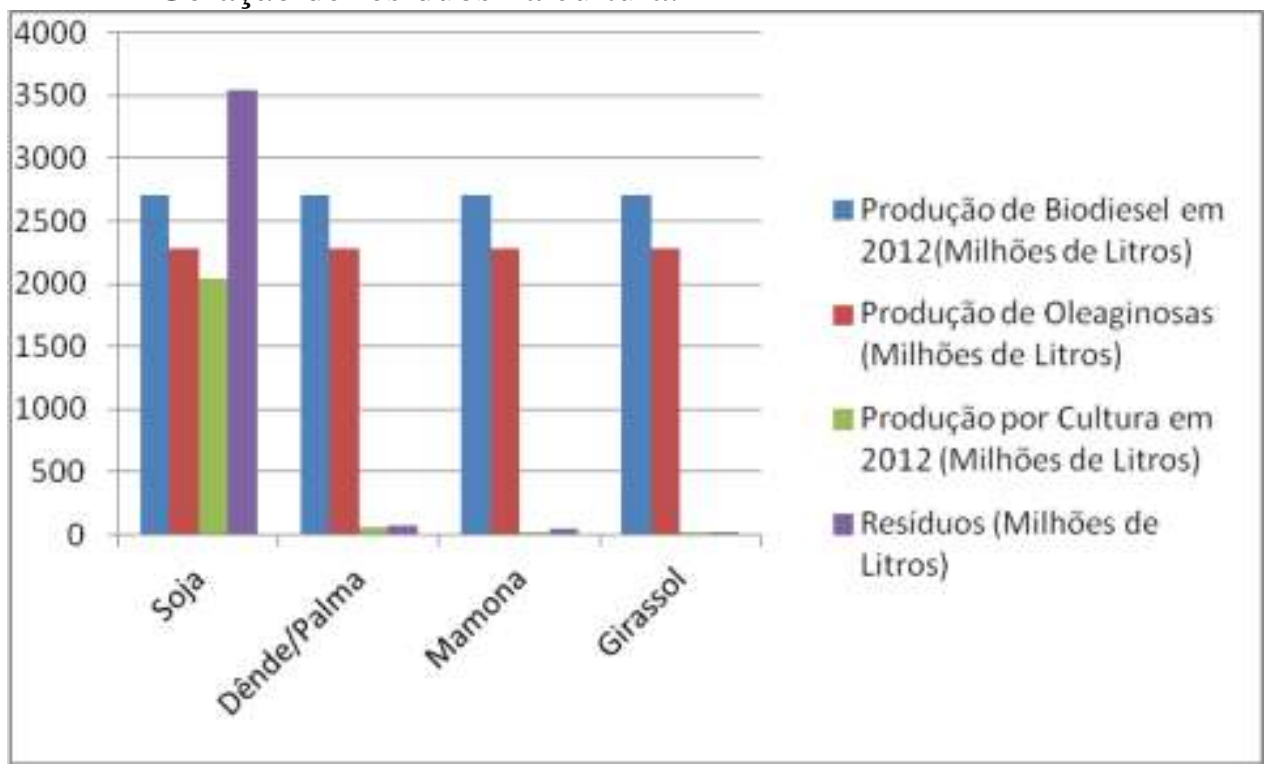

Fonte: Adaptado da ANP (2009). 


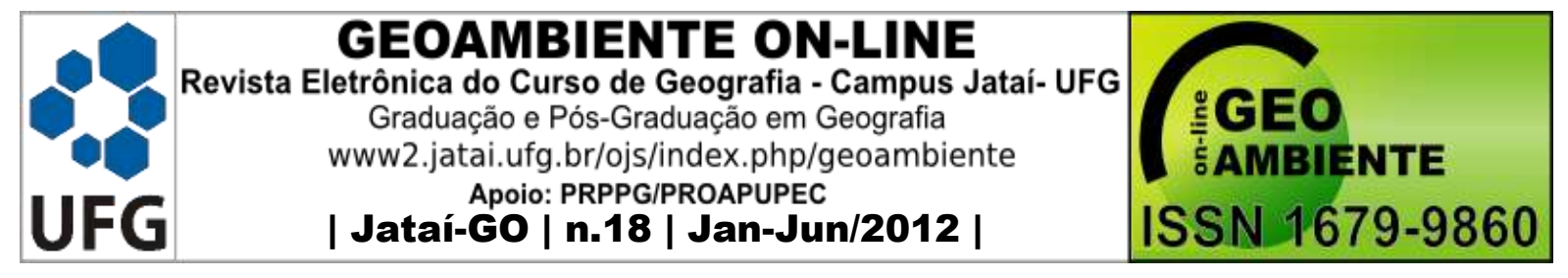

\subsection{Possibilidades de Utilização De Resíduos}

\section{I) Dendê (Elaeis Guineensis L.)}

A região Norte do Brasil é que apresenta as características climáticas ideais para o cultivo de dendê, sendo os estados do Pará, Amazonas e Amapá, além da Bahia na região Nordeste, os mais promissores. Vários processos operacionais são utilizados para obter o produto acabado. O primeiro deles produz o óleo bruto extraído do mesocarpo do fruto, que na sua segunda fase pode ser refinado ou também fracionado onde são obtidas frações sólidas (estearina) e líquidas (oleína) (SLUSZZ \& MACHADO, 2006). Segundo a AGROPALMA (2011) a estearina pode ser usada na indústria alimentícia, substituindo gorduras hidrogenadas sendo livres de ácidos graxos trans.

As folhas dessa cultura são removidas na colheita e durante as rondas de poda de uma a três vezes por ano, nas plantas adultas cada palmeira produz uma média de 25 folhas por ano, ou10 t de matéria seca por hectare, esse material pode ser reciclado no campo aportando aproximadamente $45 \%$ de fertilizante que a cultura exige. A decomposição é feita no próprio campo, de forma natural e com rápida mineralização (SOLANO, 1984).

Segundo HUSIN et al. (1986), na Malásia, utilizam-se as folhas podadas como fonte de fibras na fabricação de painéis, papel e polpa.

As folhas podem ser espalhadas sobre as entrelinhas provendo uma cobertura do solo que ajuda a minimizar os efeitos erosivos das chuvas, conservar a umidade do solo e dificultar o desenvolvimento de ervas daninhas (FURLAN,2006).

Os estipes velhos podem ficar no campo e fornecer grandes quantidades de nutrientes, segundo SINGH (1994), no total de matéria seca, 75 t/há para estipes, fornecendo $\mathrm{N}, \mathrm{P}, \mathrm{K}$.

Quanto aos resíduos gerados na usina temos, por exemplo, o engaço que é o suporte fibroso que sustenta o fruto que de acordo com FURLAN (2006) podem ser devolvidos ao campo como cobertura, incinerados para produzir cinza ou utilizados na usina como fonte extra de energia. A grande quantidade de matéria orgânica e de nutrientes nos engaços tornaos excelentes "mulch". 


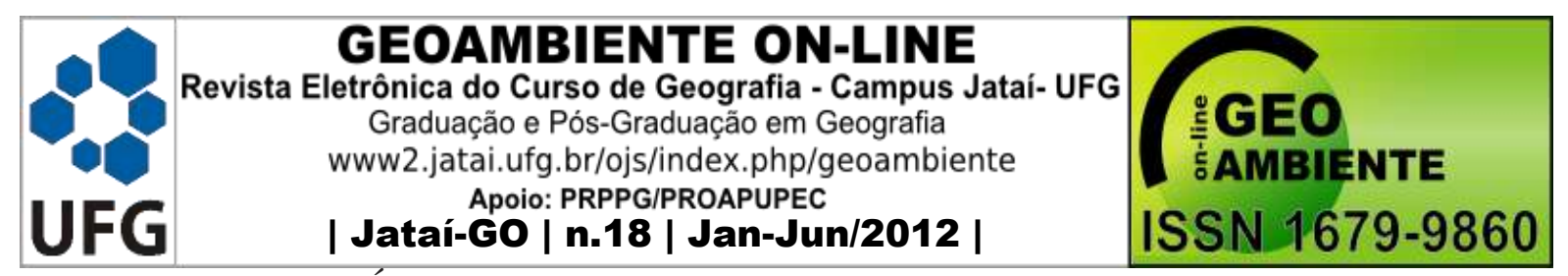

FURLAN JÚNIOR et al. (1998), obtiveram resultados de 2 anos, para dendezeiros com 4 e 5 anos de idade, comprovando que 10 hectares em produção geram material orgânico suficiente para adubar 1 hectare. A taxa de decomposição dos cachos vazios foi de aproximadamente $85 \%$ após 1 ano e que o efeito "mulching" na disponibilidade de nutrientes, principalmente potássio, ocorreu em grande parte até aos 12 meses depois da aplicação do material orgânico, o que se verificou desde o início do processo. $\mathrm{O}$ uso de engaços como cobertura do solo promove o aumento dos níveis foliares de N, P e K logo aos 6 meses após a aplicação, quando comparados com os das plantas que receberam somente fertilização inorgânica (FURLAN,2006). De acordo com o mesmo autor esses engaços parcialmente desidratados, podem ser utilizados como energia extra em caldeiras das plantas extratoras de óleo de palma devido ao seu poder calorífero de $3940 \mathrm{kcal} / \mathrm{kg}$ e alto teor fibras, e ainda pode ser usado como composto orgânico para fertilizar o solo por ser rico em Húmus e Potássio.

Da polpa, depois de extraído o óleo, sobra uma fibra que pode servir para alimentar as caldeiras à vapor ou aproveitada ainda como adubo.Depois de queimadas na caldeira essas fibras geram uma quantidade apreciável de cinzas.Essas cinzas, além dos nutrientes que possuem em sua composição química, também possuem bases que servem para neutralizar a acidez do solo, funcionando, desse modo, como corretivo e como fertilizante, cujos efeitos podem diferir dependendo do tipo de solo (SANTOS et al. 1995; PRADO et al. 2002).

Com as sementes, depois de retirado o óleo de palmiste, é feita a torta de palmiste, que tem teor de proteína de $15 \%$, podendo ser utilizada na alimentação animal. A casca, com alto poder calorífico, pode ser comercializada e empregada como combustível, cobertura em sacos de muda, no revestimento de estradas ou como matéria-prima em usinas de carvão.

O exposto revela que da cultura do dendê se utiliza tudo, podendo proporcionar uma renda extra e empregos para pequenos produtores da Região Norte do país (SLUSZZ \& MACHADO, 2006).

\section{II- Girassol (Helianthus annuus L.)}

O girassol é considerado um cultivo rústico que se adapta facilmente às condições edafoclimáticas pouco favoráveis e não requer manejo especializado, sendo preferencialmente recomendado para as regiões Sudeste e Sul do Brasil. Também na região do Cerrado, pode ser plantado de modo a aproveitar as últimas chuvas do verão. Além da extração do óleo, o girassol possui outros usos. As hastes podem originar material para forração acústica em 


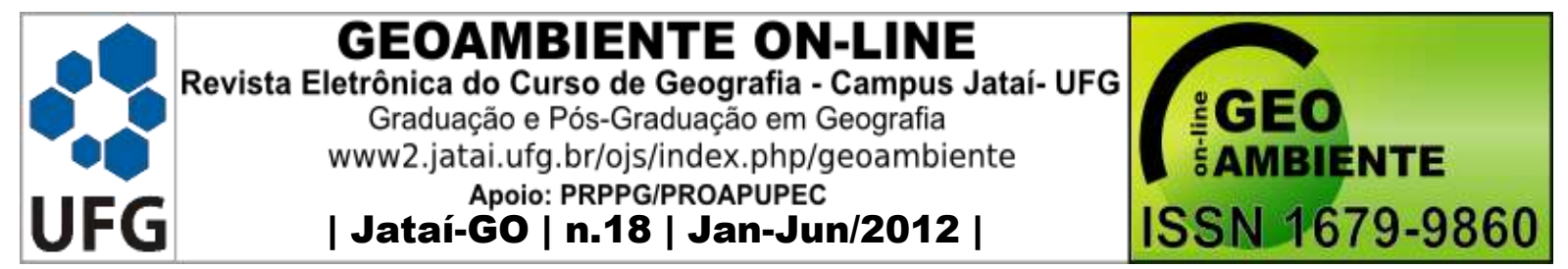

paredes, junto com as folhas, podem ser ensiladas para alimentação animal e também promover uma excelente adubação verde, assim como suas raízes pivotantes que promovem uma considerável reciclagem de nutrientes e aumento da matéria orgânica do solo quando deixado após a colheita. (SLUSZZ \& MACHADO, 2006).

Dos processos mecânicos de extração do óleo, com menor eficiência temos a torta de girassol que ainda possui $18 \%$ de gordura na matéria seca (MS), que pode ser utilizada na alimentação animal, no estudo realizado por CHUNG et. al.(2009) a análise bromatológica comprovou a potencialidade de uso na alimentação de aves.

DAGHIR et al. (1980) afirma que o farelo de girassol (resíduo da semente com ou sem casca, sem o óleo) apresenta bons resultados na alimentação de aves , e de acordo com SILVA et al. (2002) tem efeito positivo na proporção de $15 \%$ na ração de suínos, em ruminantes pode ser usado sem restrições se apresentando como um bom suplemento proteico e de boa palatabilidade.

O resíduo resultante da extração de óleo pode ser usado para processamento de compósitos poliméricos de fibra natural, triturando-se a torta e retirando o óleo residual (SCHNEIDER,2006).

DALLA COSTA et al.(2008), mostra que a casca do girassol pode ser usada como cama sobreposta, em sistema de criação de suínos com a função de absorver e transformar os dejetos produzidos pelos animais, proporciona melhoria de ambiente pela redução do odor causado pelas fezes dos animais e ainda evita que essas fezes provoque contaminação do lençol freático, poluindo águas superficiais e subterrâneas.

\section{III- Mamona (Ricinus communis L.)}

A torta de mamona é o mais tradicional e importante produto, e é obtida como residual da extração do óleo das sementes. De acordo com MACHADO et al.1954) a torta da mamona pode ser usada como matéria prima para a produção de aminoácidos, plásticos, em especial os biodegradáveis, colas, inseticidas e ainda segundo experimentos realizados por ACHTAR \& MOHMOOD (1996) mostra que a torta da mamona promove o aumento da população de agentes do solo que são predadores de nematóides causadores de doenças em plantas. 


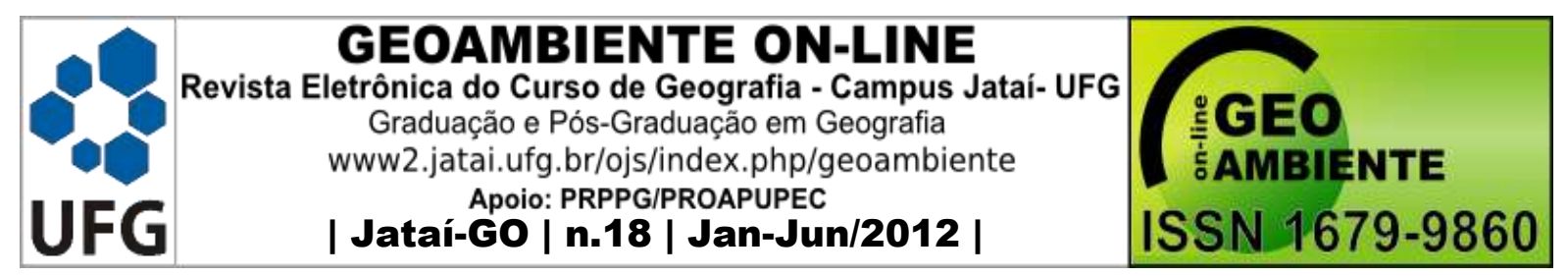

O uso predominante da torta, é como adubo orgânico e é de boa qualidade, eficiente na recuperação de terras esgotadas, devido ao seu potencial de mineralização dos nutrientes (SLUSZZ \& MACHADO, 2006).

O uso deste resíduo na ração animal, agregaria maior valor ao produto, porém depende de tecnologia para a destoxicação e desalergenização em escala industrial que ainda não estão disponíveis .No entanto, dados da pesquisa de TOKARNIA E DOBEREINER (1997), demonstram que uma vez destoxicada, pode ser direcionada para o uso rotineiro na alimentação de ruminantes,e de outras criações como a piscicultura e avicultura.

Outro produto é a casca que de acordo com estudos realizados por KNOTHE (2002), pode ser gaseificada através de um leito fixo ou fluidizado, obtendo-se o gás pobre, que será utilizado na geração de energia térmica, elétrica e mecânica através de uma turbina e um gerador, podendo ser uma alternativa para a geração de energia nas unidades beneficiadoras de biodiesel.

Nos experimentos de SILVA et.al (2004) temos as folhas e ramos frescos das diversas variedades da planta de mamona, utilizada para a produção de óleos essenciais.

\section{IV-Soja (Glycine Max)}

A casca da soja é o resíduo de maior valor comercial em uma indústria processadora de soja, sendo que a sua principal utilização é como ingrediente na alimentação animal, outra utilização é a aplicação desta casca no farelo de soja para equilibrar o teor de proteína fazendo a casca ser vendida à preço de farelo (PUKASIEWICZ et al.2004).

De acordo com QUEIROZ (2000), outro resíduo gerado no processamento de soja é a borra de óleo que corresponde a $0,04 \%$ dos resíduos sólidos gerados. Este resíduo é obtido no fundo dos tanques de óleo bruto e pode ser utilizado como matéria prima na obtenção de glicerol e ácido graxo.

Existe também um resíduo da cultura, que se obtém com a limpeza dos equipamentos e varrição da soja e pode ser utilizado no solo como adubo, pois contém alto teor de Fósforo (P) e Potássio (K) em sua composição (PUKASIEWICZ et al.2004).

O farelo da soja é obtido depois da extração do óleo da semente,e é tradicionalmente a fonte de proteína básica da dieta de bovinos leiteiros. Poucas são as alternativas para substituí-lo e raramente se consegue o mesmo resultado, quando a substituição é total. A alta 


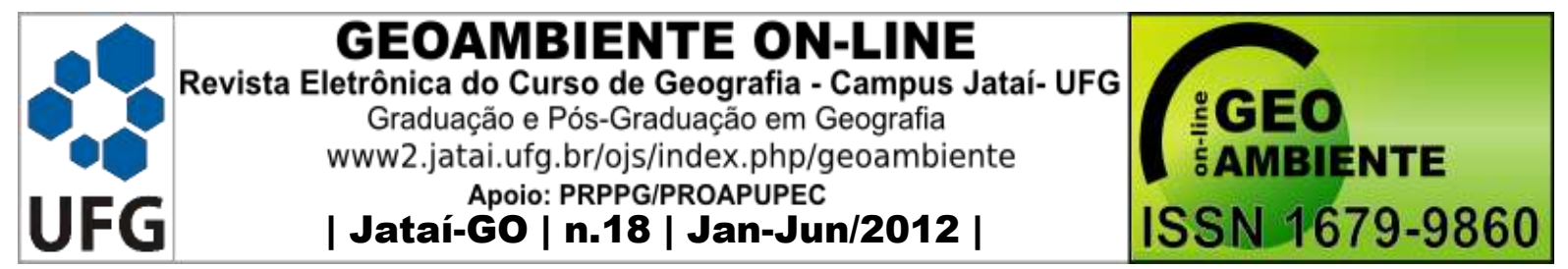

concentração protéica do farelo de soja (44 a 46\% PB na matéria seca) facilita a formulação das dietas (PUKASIEWICZ et al.2004).

\section{4- Conclusão}

Com este trabalho conclui-se que com o aumento na porcentagem de biodiesel no óleo diesel haverá o aumento do cultivo de oleaginosas, que resultará em um aumento significativo na quantidade de resíduos produzidos, e é possível fazer o aproveitamento total das culturas oleaginosas, usando resíduos sólidos orgânicos produzidos no campo, na colheita,e no processo industrial de produção de óleo vegetal. Historicamente, tem-se usado o termo subproduto para designar materiais derivados da agroindústria, como alguns desses resíduos, no entanto, pelo fato destes apresentarem valor econômico e importância para a cadeia produtiva até maior que os produtos considerados primários (ex. farelo de soja) têm-se adotado o termo co-produto;

Dentre as culturas aqui analisadas, o Dendê é o que apresenta maior viabilidade para a exploração de biodiesel, devido seu alto rendimento em óleo/há, razoável quantidade de resíduos gerados e o aproveitamento integral desses resíduos ( campo e processo);

Diante desses dados apresentados aqui, fica evidente os benefícios agronômicos e econômicos do uso desses materiais, bem como a melhoria ambiental com o seu manejo adequado;

Esses novos produtos podem representar mais uma fonte de renda para os produtores e se tornarem produtos potencialmente competitivos no mercado, fortalecendo a economia, melhorando as condições ambientais e sociais (como a geração de empregos), além de induzir pesquisas para o aprimoramento de sua utilização como matérias-prima.

Sob o ponto de vista econômico e ambiental a reciclagem, ou tratamento dos resíduos pode até eliminar riscos de poluição, evitando assim, vetores de doenças e animais peçonhentos. Na Amazônia, por exemplo, o aproveitamento desses descartes pode contribuir imensamente, gerando atividades na pequena agricultura e pecuária, trazendo inúmeros benefícios sociais e fortalecendo a agricultura familiar.

\section{Referências}




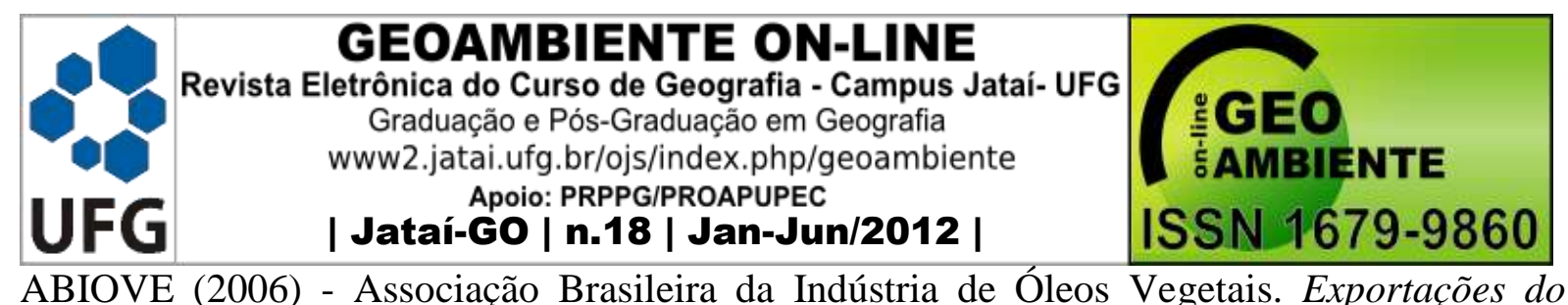

Complexo Soja. Disponível em http://www.abiove.com.br/export.html. Acesso em novembro de 2011.

AGÊNCIA NACIONAL DE PETRÓLEO - ANP. Boletim Mensal de Biodiesl- SRP de 01/12/2009. Disponível em < HTTP.www.anp.gov.br/biodisel/boletim> acesso em $17 / 10 / 2011$.

AGROPALMA. Disponível em: < http://www.agropalma.com.br>. Acesso em 14/11/11.

AKHTAR, M.; MAHMOOD, I. Control of plant-parasitic nematodes with organic and inorganic amendments in agricultural soil. Applied Soil Ecology, v.4, p.243-247, 1996.

AMARAL, Daniel Furlan. Desmistificando o Programa Nacional de Produção e Uso do Biodiesel- A Visão da Indústria Brasileira de Óleos Vegetais - Associação Brasileira das Indústrias de Óleos Vegetais - ABIOVE, São Paulo, Agosto, 2009, 21p.

COSTA, Fabiana Xavier. Composição química da torta de mamona. I Congresso de Mamona, Energia e sustentabilidade. 2002, Campina Grande-PB.

CHUNG, S., OLIVEIRA, C.R.C. SOUZA, J.G., AGUIAR, E.M., BRASIL, D.F. Avaliação físico-química da torta de girassol (helianthus annuus l.) Para a utilização na alimentação animal. Zootec.2009, Águas de Lindóia/SP.

DAGHIR, N.J.; RAZ, M.A.; UWAYJAN, M. Studies on the utilization of full fat sunflower seed in broiler ration. Poultry Science, v.59, n.10, p.2273-2278, 1980.

DALLA COSTA et al. Desempenho, características de carcaça, qualidade da carne e condição sanitária de suínos criados nas fases de crescimento e terminação nos sistemas de confinamento e de cama sobreposta. Ciência Rural, Santa Maria, v. 38, n. 8, p. 2307-2313, Nov, 2008.

EMPRESA DE PESQUISA ENERGÉTICA - EPE. Plano Decenal de Energia-2008-2017. Disponivel em <http://www.epe.gov.br/Estudos/Paginas/.> Acesso em 17 der novembro de 2011.

FURLAN JÚNIOR, J. ; TEIXEIRA, L. B.; OLIVEIRA, R. F. de. Sistema de cobertura morta utilizando cachos vazios de dendê em dendezais e sua economicidade. Belém, PA:

Embrapa-CPATU, 1998. p.4 (Embrapa-CPATU. Comunicado técnico, 81).

FURLAN JÚNIOR, J.. Dendê: manejo e uso dos subprodutos e dos resíduos. Embrapa Amazônia. Belém, PA: Embrapa Amazônia Oriental, 2006.37p. (Embrapa Amazônia Oriental. Documento, 246). 


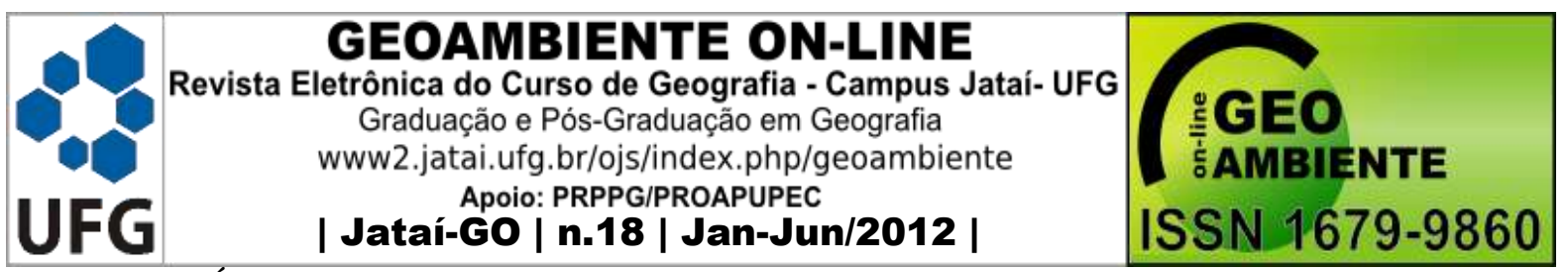

FURLAN JÚNIOR, J.; KALTNER, F.J.; AZEVEDO,G.F.P. et al. Biodiesel: Porque tem que ser dendê. Belém, PA: Embrapa Amazônia Oriental, Palmasa, 205p. 2006.

GOES, T.; ARAUJO, M.; MARRA, R. Novas fronteiras tecnológicas da cana-de-açúcar no Brasil.Revista de política Agrícola. Publicação da Secretaria de Política Agrícola do Ministério da Agricultura, Pecuária e Abastecimento. 126p.( Publicação Trimestral .Ano XVIII - No 1). BRASIL,2009.

HUSIN, M.; Hj. HASSAN, A. H.; MOHAMMED, A. T. Availability and potencial utilisation of oil palm trunks and fronds up to the year 2000. Kuala Lumpur: Palm Oil Research Institute of Malaysia, 1986. p.17 (PORIM. Occasional Paper, n. 20).

LOUREIRO, M.C. Torta de semente de mamoeira na alimentação animal. Revista Ceres, v.11.n.66. p.290-294, 1962.

MACHADO, R. M. de; BARREIRA, H, A.; FARIA E. V.; MACHADO, D. D. O farelo de mamona desintoxicado na alimentação de novilhas leiteiras. Rio de janeiro: Instituto de Zootecnia, 1957. 12p. (publicação 41).

MELlO, W.C.; SANTOS, A.S. DOS., SANTA ANNA, L.M.M. et al. Acid and enzymatic hydrolisis of the residue from castor bean ( Ricinus communis L.) oil extracton for ethanol production: detoxification and biodiesel process integration. J.Braz. Chem. Soc. 19:418-425, 2008a.

MOHD HASHIM, T.; YEOW, K. H. Effect of frond removal on fresh fruit bunches production. PORIM Workshop Proceedings, n.11, p.227-240, 1987.

NOGUEIRA, L. A. H. Agencia Nacional de Energia Elétrica, Dez, 2005. .http://www.aneel.gov.br.

PRADO, R. M.; CORRÊA, M. C. de M.; NATALE, W. Efeito da indústria de cerâmica no solo e na nutrição de mudas de goiabeira. Acta Scientiarum, v.24, p. 1493 - 1500, 2002.

PETROBRAS biocombustíveis. Disponível: < http://www.petrobras.com.br/pt/energia-etecnologia/fontes-de-energia/biocombustiveis >. Acesso em: 13/10/11.

PUKASIEWICZ, S.R.M.; OLIVEIRA, I . L.; PILATTI, L.A. Estudo de caso: gerenciamento de resíduos sólidos industriais em uma indústria processadora de soja. XI SIMPEP Bauru, SP,2004.

QUEIROZ, L. (2000) - Óleo de Soja, Óleo Ácido de Soja e Sebo Bovino Como Fontes de Gordura em Rações de Frangos de Corte. Rev. Bras. Cienc. Avic. vol.2 no.3 Campinas Sept. RUSSO M.A.T. Tratamento de Resíduos Sólidos, Coimbra, 2003. 


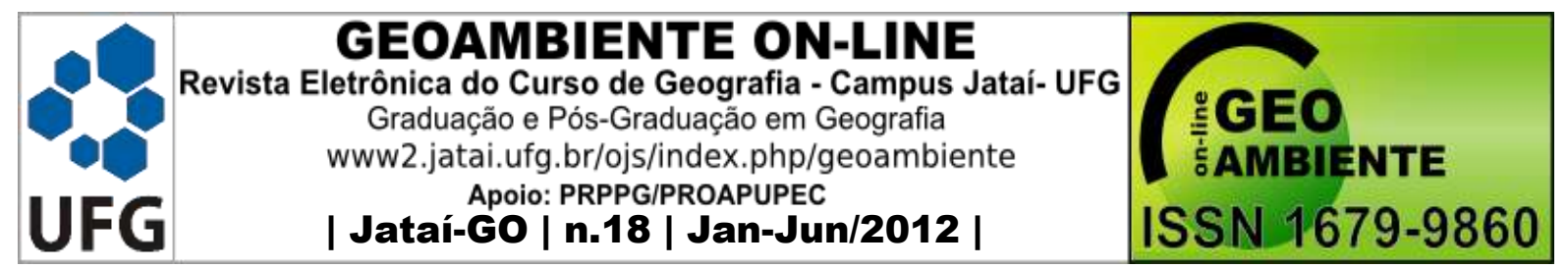

SANTOS, J. A.G. Avaliação do potencial corretivo da cinza, oriunda de biomassa vegetal, comparada ao calcário. In: Congresso brasileiro de ciência do solo, 25. Resumos expandidos. Viçosa: sociedade brasileira de ciência do solo: universidade federal de viçosa, 1995. v.2, p.1148-1150.

SCHNEIDER, R. de C. de S. ; RODRIGUEZ , A. L.; MÄHLMANN C. M. ; BALBINOT, N. e RADKTE, L.; BERGONSKI R. Obtenção e caracterização de compósitos de termoplásticos e resíduos da produção de óleo de girassol. $17^{\circ} \mathrm{CBECIMat} \mathrm{-} \mathrm{Congresso}$ Brasileiro de Engenharia e Ciência dos Materiais.2006, Foz do Iguaçu- PR.

SILVA, C. A., PINHEIRO, J. W.; FONSECA, N.A.N; CABRERA, L.; NOVO, V.C.C. ; SILVA, M.R.C.C.; CANTERI, R.C.; HOSHI, E.H.; Farelo de Girassol na Alimentação de Suínos em Crescimento e Terminação:Digestibilidade, Desempenho e Efeitos na Qualidade de Carcaça. R. Bras. Zootec., v.31, n.2, p.982-990, 2002.

SILVA, V.F.; CARDOSO, M.G.; MUNIZ, F.R.; FRAGA,A.C.; NETO, P.C. Avaliação dos teores de óleos essenciais de variedades de mamona. I congresso Brasileiro de mamona.Energia e Sustentabilidade.2004, Campina Grande-PB.

SINGH, G. Management and utilisation of oil palm by-products. Kuala Lumpur, Malaysia: PORIM,1994. p. 19-48.

SLUSZZ, T. \& MACHADO, J. A. D. Características das potenciais culturas matériasprimas do biodiesel e sua adoção pela agricultura familiar. Fortaleza: XLIV CONGRESSO DA SOBER“Questões Agrárias, Educação no Campo e Desenvolvimento”, 2006.

SOLANO, G. R. Principales Sub-productos de las plantas extractoras de aceite.[S1.:s.n.] 1984.

TOKARINA, C. H.; DOBEREINER, J. Imunidade cruzada pelas sementes de Abrus precatorius e Ricinus communis em bovinos. Pesquisa Veterinária Brasileira, v.17, n.1, p.2535, 1997. 